\title{
Comparative study of anthropometric measurement and body composition between soccer players from different competitive levels, elite and sub-elite
}

\author{
Masanovic B. ${ }^{1 \mathrm{ABCDE}}$, Milosevic Z. ${ }^{2 \mathrm{ABCD}}$, Bjelica D. ${ }^{1 \mathrm{ABDE}}$ \\ ${ }^{1}$ Faculty for Sport and Physical Education, University of Montenegro, Montenegro \\ ${ }^{2}$ Faculty of Sport and Physical Education, University of Novi Sad, Serbia
}

Authors' contribution: A - Study design; B - Data collection; C - Statistical analysis; D - Manuscript Preparation; E - Funds collection.

\begin{abstract}
Purpose:

The purpose of this study was to describe anthropometric characteristics and body composition of soccer players from different competitive levels, elite and sub-elite as well as to make comparison between them.

Material: $\quad$ Seventy-seven subjects were enrolled in this study, divided into three groups: twenty-six elite soccer players, twenty sub-elite soccer players and thirty-one healthy sedentary subjects. All subjects were assessed for anthropometric measurements required for the calculation of body composition variables using standardized procedures which were recommended by previous studies. Data was analyzed by using SPSS and the descriptive statistics were expressed as a mean (SD) for each variable, while the ANOVA and the LSD Post Hoc tests were carried out to discover effects of each type of sport.

Results: $\quad$ The results showed that a significant difference was found in weight, body mass index, bone content and body fat, while a significant difference was not found in two remaining variables, height and muscle mass.

Conclusions: $\quad$ Therefore, these findings may give coaches from the region better working knowledge and thus provide knowledges for soccer experts which will help them to select talented players as best as possible.

Keywords: morphological characteristics, body composition, male athletes, senior.
\end{abstract}

\section{Introduction}

Based on a survey conducted by the Fédération Internationale de Football Association we find that 269.610 million men and women are active in playing football [1]. This incredible number represents $4.13 \%$ of the world's population, and $10 \%$ of them are women. Of the number mentioned above, 226.265 million are unregistered occasional players, and 38.287 million are registered players. The registered players include 113.000 professional soccer players, 15.481 million amateur league players aged 18 and older, 21.548 million young players up to 18 years old, 1.112 million futsal players and 33000 beach soccer players. From the same sources, we find that there are 301.000 registered clubs and 1.752 million teams in the world. Also, that the increase of football consumers between 2000 and 2006 is clearly visible. Number of registered players increased by $23 \%$ in this period and the number of occasional unregistered players by $7 \%$. Hence, with 242 million men and women active in playing football in 2000 , the total figure reached the number of 265 million men and women active in playing football in 2006. So many interested people obligate scientists from around the world to seriously deal with this field of sport and to help young people who want to compete to find their place in such a complex structure of the organization.

It is obvious that the desires and motives that encourage each individual to deal with this sport are not the same. Some have the desire to be actively engaged in soccer and choose this sport as a profession, while others o) Masanovic B., Milosevic Z., Bjelica D., 2019

doi:10.15561/18189172.2019.0602 want to play soccer recreationally and through it satisfy some completely other desires, such as the maintenance of psychophysical abilities at the optimum level. For such a form of playing free choice, and proper medical control are characteristic [2-5]. Playing soccer at an amateur league level is reflected in the massive number of recipients and the widespread distribution in each environment [6]. On the contrary, elite soccer can be defined as an activity aimed at achieving the greatest accomplishments in sport, and we can mark the sport result as the basic measuring unit of success [7, 8].

The focus towards the greatest sport results and professional soccer is very dependent on the timely selection of players [9]. In elite soccer, experts are constantly looking for the most effective formula for recognizing and developing talented young players, because their goal is to find those players who are, based on their attributes, the most similar to top-level and already proven players [10].

In order to achieve this goal, they have to be focused on the long-term development of soccer players, because different factors may predispose individuals towards a successful career, and identifying characteristics that distinguish performers can be very difficult $[11,12]$.

Some answers to this issue can be detect by comparing the anthropometric characteristics and the body composition of players of elite ranks of competition and the lower-ranked players [13-15]. Comparisons between players exposed to systematic training with already highly selected players can help to establish the distinguishing features of expertise and to identify the factors that 
determine a player's potential to progress to higher levels of play [16, 17].

The purpose of this study is to describe the anthropometric characteristics and body composition of the soccer player of different levels of competition, to examine the differences between two competitive levels, elite and sub-elite, and thus provide soccer experts with knowledges which will help them to select talented players as best as possible.

\section{Material and Methods}

Participants: Seventy-seven male athletes were enrolled in this study. They were divided into three groups: twenty-six elite soccer players (23.23 \pm 3.35 yrs.) from the Serbian Premier League, twenty sub-elite players (23.60 \pm 4.74 yrs.) from the Fifth Serbian League and thirty-two healthy sedentary subjects from the same country (24.94 \pm 3.10 yrs.). Testing was conducted in the winter preparation period.

Procedure: All subjects were clinically healthy and had no recent history of infectious disease, asthma or cardio-respiratory disorders. All of them gave their written consent and the local ethics committee approved the protocol of the study. All subjects were assessed for the twenty anthropometric measures required for the calculation of body composition variables, using the standardized procedure recommended by the International Biological Program (IBP) [18] standards respecting the basic rules and principles related to the parameter choice, standard conditions and measurement techniques, as well as the standard measuring instruments adjusted before measurement was carried out. Height and weight were measured in the laboratory with the subject dressed in light clothing. Height was measured to the nearest $0.1 \mathrm{~cm}$ using a fixed stadiometer, and weight was measured to the nearest $0.1 \mathrm{~kg}$ with a standard scale utilizing a portable balance. Skinfolds (mm) were measured at six sites: triceps skinfold thickness, forearm skinfold thickness, thigh skinfold thickness, calf skinfold thickness, chest skinfold thickness and abdominal skinfold thickness (using a skinfold caliper). The circumferences $(\mathrm{cm})$ were measured at eight sites: minimum and maximum circumference of the upper arm, minimum and maximum circumference of the forearm, minimum and maximum circumference of the upper leg, minimum and maximum circumference of the lower leg (using a anthropometric tape). At last the following diameters were measured to the nearest $0.1 \mathrm{~cm}$ : elbow diameter, wrist diameter, diameter of the knee, diameter of the ankle (using a small siding caliper). To reduce measurement variation, the same investigator examined all of the subjects. Body mass index (BMI) was calculated as body mass in kilograms divided by height in meters squared $\left(\mathrm{kg} / \mathrm{m}^{2}\right)$. The values of bone, muscular, and fat contents of body composition were acquired by distributing all the measured variables in formulas by Mateigka [19].

Statistical analysis: The data obtained in the research was processed using the application statistics program SPSS 20.0, adjusted for use on personal computers. The descriptive statistics were expressed as a mean (SD) for each variable. Analysis of the variance (ANOVA) and the LSD Post Hoc test were carried out to detect the effects for each level of competition (elite or sub-elite) on each variable: body height, body weight, body mass index (BMI), and muscle, bone and fat content of the body, as well as to control it by sedentary subjects. The significance was set at an alpha level of 0.05 .

\section{Results}

Anthropometric characteristics of subjects are shown in Table 1. There were significant differences in four out of six variables among the groups. Hence, a significant difference was found for weight $(\mathrm{F}=3.56)$, body mass index $(\mathrm{F}=3.23)$, bone content $(\mathrm{F}=4.27)$ and body fat $(\mathrm{F}=27.72)$. There is no significant difference in the remaining two variables: height $(\mathrm{F}=1.78)$ and muscle mass $(\mathrm{F}=2.16)$.

Significant differences of anthropometric characteristics among particular sports are shown in Figure 1. The LSD Post Hoc test indicated that subjects from the control group were heavier and have higher body mass index than elite soccer players and subelite soccer players who have the lowest value of both mentioned parameters. When it comes to bone content, sub-elite soccer players have highest percentage, while subjects from the control group have lowest percentage of bone content. Lastly, elite soccer players had the lowest percentage of body fat, while subjects from the control group had the highest percentage body fat. It was not found any significant difference for the muscle mass, but

Table 1. Descriptive data and ANOVA of male athletes enrolled in the study $(n=71)$

\begin{tabular}{lllll}
\hline Variables & Elite Soccer $(\mathbf{n}=\mathbf{2 6})$ & $\begin{array}{l}\text { Sub-Elite Soccer }(\mathbf{n}=20) \\
\text { Mean } \pm \text { Standard Deviation }\end{array}$ & Control $(\mathbf{n = 3 1 )}$ & ANOVA \\
\hline Height $(\mathrm{cm})$ & $182.11 \pm 6.73$ & $179.77 \pm 7.51$ & $183.72 \pm 7.60$ & $0.175^{\wedge}$ \\
Weight $(\mathrm{kg})$ & $80.10 \pm 7.13$ & $77.40 \pm 16.04$ & $86.74 \pm 14.68$ & $0.03^{*}$ \\
BMI $\left(\mathrm{kg} / \mathrm{m}^{2}\right)$ & $24.11 \pm 1.14$ & $23.74 \pm 3.30$ & $25.61 \pm 3.49$ & $0.045^{*}$ \\
Muscle mass (\%) & $49.90 \pm 2.78$ & $49.66 \pm 3.18$ & $48.32 \pm 3.27$ & $0.123^{\wedge}$ \\
Bone content (\%) & $15.77 \pm 0.92$ & $16.07 \pm 2.20$ & $14.78 \pm 1.78$ & $0.018^{*}$ \\
Body fat $(\%)$ & $9.64 \pm 1.60$ & $15.73 \pm 4.67$ & $18.51 \pm 5.89$ & $0.000^{*}$ \\
\hline
\end{tabular}

Note: $\mathrm{N}$ - number of subjects; BMI - body mass index; ${ }^{\wedge}$ - non-significant; ${ }^{*}$ - significant difference between groups. 

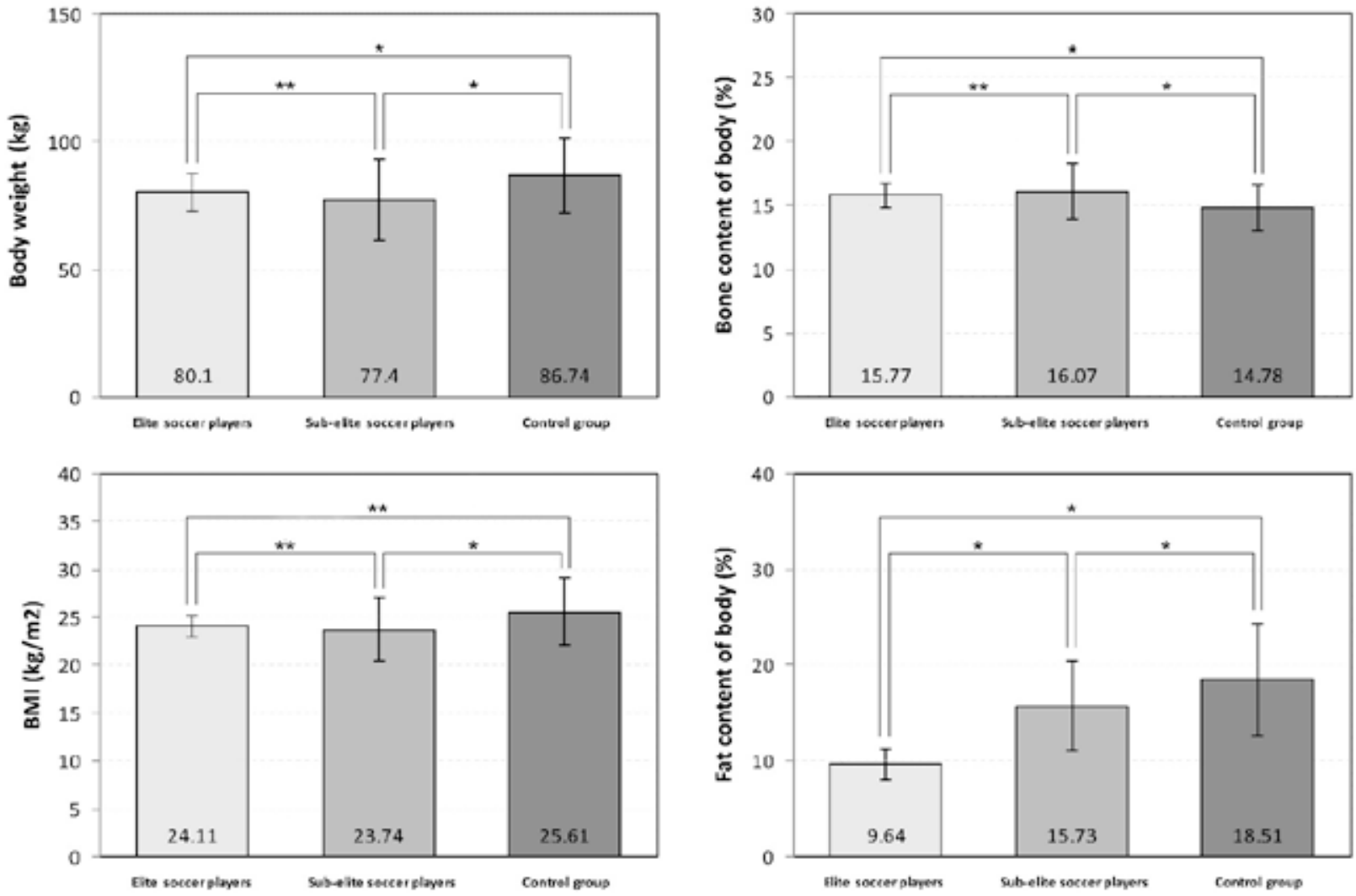

Legend: * - significance; **-non-significance.

Figure 1. LSD Post Hoc test for the different parameters among the subjects

it was noticed that elite soccer players had the highest muscle mass, while subjects from the control group had the lowest values.

\section{Discussion}

Some previous studies suggest that there has been a tendency to recruit taller and heavier soccer players [20]. The absence of differences between soccer players and subjects from the control group in this study raises doubts that the selection process has been carried out correctly, especially since even elite soccer players are shorter than subjects from the control group. Nevertheless, it has to be considered that the average body height of all participants in the FIFA 2018 World Soccer Cup that took place in Russia 2018 was 182.41 centimeters, while the average body height of the national team of France, who won the first place on championship, was 183.3. On the other hand, Luka Modric and Kylian Mbappe, the best player and the best young player of the FIFA 2018 World Cup in Russia 2018, were 172 and 178 centimeters tall, while the most valuable French and Belgian players, Antoine Griezmann and Eden Hazard, were 175 and 173 centimeters tall. Mentioned official statistical data proved that elite soccer players involved in this study were tall enough and did not lag behind the top World players, and that the selection of players was well done, which is not a surprise given that the high percentage of very high subjects is a characteristic of people from this area [2123]. Likewise, the tendency to recruit taller soccer players is not unsworn in the scientific literature yet [24-26]. When it comes to sub-elite players, they are somewhat lower than the other two remaining group of respondents, but this is consistent with previous literature that points out that sub-elite players have a lower average height than the elite $[13,27]$.

However, we found that subjects from the control group have the highest body mass and highest values of body mass index. The values of both of these variables are slightly higher than in the case of elite soccer players, and significantly higher than sub-elite soccer players, which corresponds with previous studies [14, 28]. Body mass and BMI subjects from the general population are higher because their physical activity is far lower than the activity of soccer players from both groups. On the other hand, body weight and BMI elite players are higher than when it comes to sub-elite players, because the body of elite players must be stronger due to higher demands of their ranking [6].

Surprisingly, we did not find any significant differences among the groups regarding muscle mass, as it is widely known that increasing lean body mass is important to improve strength and power, relevant to sport performance [29]. However, it is not a worry factor because, fortunately, the muscle mass of soccer players from this study corresponds to the values obtained from previous studies [30], and high values of muscle mass of sub-elite soccer players and subjects from control group point out the high quality of their training, i.e. the correct diet. 
On the contrary, the percentage of bone content of elite soccer players is of the highest values, slightly higher than the percentage of bone content of sub-elite soccer players, and significantly higher than those of subjects from the control group, which supports the previous knowledges of positive impact of physical activity on bone mass [31, 32].

Lastly, a low percentage of body fat of elite soccer players from this study, which was significantly lower than the percentage of body fat of sub-elite soccer players and subjects from the control group, showed that elite players have a high level of physical performance. Also, sub-elite soccer players had a significantly lower percentage of body fat than subjects from the control group, which is also expected, because in many previous studies soccer has been recognized as an aerobic sport $[33,34]$ in which, as it is known, excessive fat mass compromises physical performance $[35,36]$. Certainly, it is very important to remember that the National Strength and Conditioning Association indicates that body fat percentages should not be lowered below 7 percent, because soccer players need a certain body fat percentage to perform well enough and achieve their full playing potential.

The importance of body composition in sport performance is a primary concern in creating elite soccer players profiles as well as conditioning programs throughout a season at all levels of competitions [28]. Also, describing anthropometric characteristics and body composition of soccer players and detecting possible differences in relation to competition levels may give coaches a better working knowledge of the studied groups, and can allow them to identify the factors that determine a player's potential to progress to higher levels of play.

\section{Conclusion}

The results of this study suggest that soccer players from both competitive levels had a slightly higher percentage of muscle mass and significantly lower percentage of body fat in comparison to the control group, while that elite soccer players had slightly higher percentage of muscle mass and significantly lower percentage of body fat in comparison to the sub-elite soccer players. This study also suggests that soccer players from both competitive levels had significantly increased bone content in comparison to the control group. The part attributed to the body height is the main cause of the selection process, and lastly, the part attributed to body weight and BMI could be the main cause consequence of nutritional habits.

The limitation of this study is that testing has been carried out in the middle of the competition season, and the body composition may change during the season [37]. Accordingly, the next testing should be planned at the beginning and at the end of the season, because in that way they would have an accurate insight into the changes during the macrocycle. In this way more representative data will certainly be provided, but this does not diminish the contribution of this preliminary study, because it also contains data that can help football experts to select talented players as best as possible.

\section{Conflicts of interest}

The authors declare no conflict of interest.

\section{References}

1. Big Count 2006. Statistical Summary Report by Gender/ Category/Region. [Internet]. 2007 [cited 2007, May 31]. Available from: https://www.fifa.com/media/news/y=2007/ $\mathrm{m}=5 /$ news $=$ fifa-big-count-2006-270-million-people-activefootball-529882.html

2. Gardašević J, Georgiev G, Bjelica D. Qualitative changes of basic motor abilities after completing a six-week training programme. Acta Kinesiologica. 2012; 6(1):70-74.

3. Gjonbalaj M, Georgiev G, Bjelica D. Differences in Anthropometric Characteristics, Somatotype Components, and Functional Abilities Among Young Elite Kosovo Soccer Players Based on Team Position. International Journal of Morphology. 2018; 36(1):41-47. https://doi.org/10.4067/S0717-95022018000100041

4. Aslan A, Salci Y, Guvenc A. The effects of weekly recreational soccer intervention on the physical fitness level of sedentary young men. Montenegrin Journal of Sports Science and Medicine. 2019; 8(1):51-59. https://doi.org/10.26773/mjssm.190308

5. Akelaitis A, Malinauskas R. The expression of emotional skills among individual and team sports male athletes. Pedagogics, psychology, medical-biological problems of physical training and sports. 2018;22(2):62-67. https://doi.org/10.15561/18189172.2018.0201

6. Gissis J, Papadopoulos C, Kalapotharakos VI, Sotiropoulos A, KomsisG,ManolopoulosE. StrengthandSpeedCharacteristics of Elite, Subelite, and Recreational Young Soccer Players. Research in Sports Medicine. 2015; 14(3):205-214. https://doi.org/10.1080/15438620600854769

7. Gardasevic J, Bjelica D, Vasiljevic I. Morphological Characteristics and Body Composition of Elite Soccer Players in Montenegro. International Journal of Morphology. 2019; 37(1):284-288. https://dx.doi.org/10.4067/S0717-95022019000100284

8. Herdy C, Costa PB, Simão R, Selfe J. Physiological profile of Brazilian elite soccer players: Comparison between U-17, U-20 and professionals. Journal of Anthropology of Sport and Physical Education. 2018; 2(3):43-47. https://doi.org/10.26773/jaspe. 180708

9. Gjonbalaj M, Georgiev G, Bjelica D. Differences in Anthropometric Characteristics, Somatotype Components, and Functional Abilities Among Young Elite Kosovo Soccer Players Based on Team Position. International Journal of Morphology. 2018;36(1):41-47. ttps://doi.org/10.4067/s0717-95022018000100041

10.Popovic S, Bjelica D, Jaksic D, Hadzic R. Comparative Study of Anthropometric Measurement and Body Composition between Elite Soccer and Volleyball Players. International Journal of Morphology. 2014; 32(1):267-274. https://doi.org/10.4067/S0717-95022014000100044

11.Nikolaidis PT, Vassilios Karydis N. Physique and body composition in soccer players across adolescence. Asian Journal of Sports Medicine. 2011; 2(2):75-82. https://doi.org/10.5812/asjsm.34782

12.Björkman I, Ehrnrooth M, Mäkelä K, Smale A, Sumelius J. Talent or Not? Employee Reactions to Talent Identification. Houman Resource Management. 2013; 52(2):195-214. 
https://doi.org/10.1002/hrm.21525

13.Paillard T, Noé F, Rivière T, Marion V, Montoya R, Dupui P. Postural performance and strategy in the unipedal stance of soccer players at different levels of competition. Journal of athletic training. 2006; 41(2):172-176.

14.Butler RJ, Southers C, Gorman PP, Kiesel KB, Plisky FJ. Differences in Soccer Players' Dynamic Balance Across Levels of Competition. Journal of Athletic Training. 2012; 47(6):616-620. https://doi.org/10.4085/1062-6050-47.5.14

15. Mohammed Z. Body composition versus body fat percentage as predictors of posture/balance control mobility and stability among football players under 21 years. Physical Education of Students. 2017;21(2):96-102. https://doi.org/10.15561/20755279.2017.0208

16.Gravina L, Gil SM, Ruiz F, Zubero J, Gil J, Irazusta J. Anthropometric and Physiological Differences Between First Team and Reserve Soccer Players Aged 10-14 Years at the Beginning and End of the Season. Journal of Strength and Conditioning. 2008; 22(4):1308-1314. https://doi.org/10.1519/JSC.0b013e31816a5c8e

17.Akbari H, Sahebozamani M, Daneshjoo A, Amiri-Khorasani M. Effect of the FIFA 11+ programme on vertical jump performance in elite male youth soccer players. Montenegrin Journal of Sports Science and Medicine. 2018; 7(2):17-22. https://doi.org/10.26773/mjssm.180903

18.Mišigoj-Duraković M, Matković B, Medved R. Morfološka antropometrija u športu [Morphological anthropometry in sports]. Zagreb, Croatia: Fakultet za fizičku kulturu; 1995.

19.Matiegka J. The testing of physical efficiency. American Journal of Physical Anthropology. 1921; 4:223-230. https://doi.org/10.1002/ajpa.1330040302

20.Gil SM, Gil J, Ruiz F, Irazusta A, Irazusta J. Anthropometrical Characteristics and Somatotype of Junior Soccer Players and Their Comparison with the General Population. Biology of Sport. 2010; 27(1):17-24. https://doi.org/10.5604/20831862.906762

21.Bjelica D, Popovic S, Kezunovic M, Petkovic J, Jurak G, Grasgruber P. Body Height and Its Estimation Utilizing Arm Span Measurements in Montenegrin Adults. Anthropological Notebook. 2012; 18(2):69-83.

22.Popovic S, Bjelica D, Molnar S, Jaksic D, Akpinar S. Body Height and Its Estimation Utilizing Arm Span Measurements in Serbian Adults. International Journal of Morphology. 2013; 31(1):271-279. https://doi.org/10.4067/S0717-95022013000100043

23.Masanovic B. Standing height and its estimation utilizing arm spam and foot length measurements in dinaric alps population: a systematic review. Sport Mont. 2018; 16(2):101-106. https://doi.org/10.26773/smj.180619

24.Almagia A, Araneda A, Sánchez J, Sánchez P, Zúñiga M, Plaza P. Somatotype and Body Composition of the Male University Soccer Team at Pontificia Universidad Católica de Valparaíso, Champions 2012-2013. International Journal of Morphology. 2015; 33(3):1165-1170. https://doi.org/10.4067/S0717-95022015000300057

25.Masanovic B, Corluka M, Milosevic Z. Comparative Study of Anthropometric Measurement and Body Composition of Junior Soccer and Handball Players from the Serbian National League. Kinesiologia Slovenica. 2018; 24(3):37-46. https://doi.org/10.4067/S0717-95022019000200612

26.Krespi M, Sporis G, Popovic S. Exponential versus linear tapering injunior elite soccer players: effects on physical match performance according to playing positions. Montenegrin Journal of Sports Science and Medicine. 2019; 8(1):17-22. https://doi.org/10.26773/mjssm.190303

27.Sæther SA. Characteristics of professional and nonprofessional football players - an eight-year followup of three age cohorts. Montenegrin Journal of Sports Science and Medicine. 2017; 6(2):13-18. https://doi.org/10.26773/mjssm.2017.09.002

28.Popovic S, Akpinar S, Jaksic D, Matic R, Bjelica D. Comparative Study of Anthropometric MeasurementandBody Composition between Elite Soccer and Basketball Players. International Journal of Morphology. 2013; 31(2):461-467. https://doi.org/10.4067/S0717-95022013000200016

29.Vila Suárez MH, Ferragut C, Alcaraz PE, Rodríguez Suárez N, Cruz Martínez M. Anthropometric and strength characteristics in junior handball players by playing positions. Archivos de Medicina del Deporte. 2008; 125(3):167-177.

30.Jeukendrup AE, Gleeson M. Sport Nutrition: An Introduction to Energy Production and Performance. Champaign, Human Kinetics, 2009.

31.Darwin C. On the Origin of Species, 1859. London: 2013. https://doi.org/10.4324/9780203509104

32.Tobin WJ. The internal architecture of the femur and its clinical significance: the upper end. The Journal of Bone and Joint Surgery. 1955; 37(2):434-434. https://doi.org/10.2106/00004623-195537020-00033

33.Santos-Silva PR, Fonseca AJ, De Castro AW, Greve JMD, Hernandez AJ. Reproducibility of maximum aerobic power (VO2max) among soccer players using a modified heck protocol. Clinics. 2007; 62(4):391-396. https://doi.org/10.1590/S1807-59322007000400004

34.Polevoy G. Development of the ability to differentiate the parameters of football players' movements taking into account their typology. International Journal of Applied Exercise Physiology. 2018; 7(2):26-31. https://doi.org/10.22631/ijaep.v7i2.268

35.Ramos-Campo DJ, Martínez-Sánchez F, EstebanGarcía P, Rubio-Arias JA, Bores CA, Clemente-Suarez VJ, Jiménez-Díaz JF. Body Composition Features in Different Playing Position of Professional Team Indoor Players: Basketball, Handball and Futsal. International Journal of Morphology. 2014; 32(4):1316-1324. https://doi.org/10.4067/S0717-95022014000400032

36.Arifi F, Bjelica D, Masanovic B. Differences in anthropometric characteristics among junior soccer and handball players. Sport Mont. 2019; 17(1):45-49. https://doi.org/10.26773/smj.190208

37.Nepocatych S, Balilionis G, O'Neal EK. Analysis of dietary intake and body composition of female athletes over a competitive season. Montenegrin Journal of Sports Science and Medicine. 2017; 6(2):57-65. https://doi.org/10.26773/mjssm.2017.09.008 


\section{Information about the authors:}

Masanovic B.; (Corresponding author); http://orcid.org/0000-0002-4939-4982; bojanma@ucg.ac.me; University of Montenegro; Cetinjski put 2, 81000, Podgorica, Montenegro.

Milosevic Z.; http://orcid.org/0000-0001-7408-2545; zoranaisns29@mail.com; University of Novi Sad; Lovcenska 16, 21000, Novi Sad, Serbia.

Bjelica D.; http://orcid.org/0000-0001-5272-528X; dbjelica@ucg.ac.me; University of Montenegro; Cetinjski put 2, 81000, Niksic, Montenegro.

Cite this article as:

Masanovic B, Milosevic Z, Bjelica D. Comparative study of anthropometric measurement and body composition between soccer players from different competitive levels, elite and sub-elite. Pedagogics, psychology, medical-biological problems of physical training and sports, 2019;23(6):282-287. https://doi.org/10.15561/18189172.2019.0602

This is an Open Access article distributed under the terms of the Creative Commons Attribution License, which permits unrestricted use, distribution, and reproduction in any medium, provided the original work is properly cited (http://creativecommons.org/licenses/by/4.0/deed.en).

Received: 10.08.2019

Accepted: 20.09.2019; Published: 30.09.2019 